Article

\title{
Determination of Sesquiterpenes in Wines by HS-SPME Coupled with GC-MS
}

\author{
Fabrizio Cincotta, Antonella Verzera *, Gianluca Tripodi and Concetta Condurso \\ Department of Chemical Science, University of Messina, Viale F. Stagno d'Alcontres, \\ 3198168 Messina, Italy
}

* Author to whom correspondence should be addressed; E-Mail: averzera@unime.it; Tel.: +39-090-6765167.

Academic Editor: Mary Boyce

Received: 26 March 2015 / Accepted: 3 July 2015 / Published: 9 July 2015

\begin{abstract}
The sesquiterpene compounds present in red wines were characterized and quantified by Headspace Solid-Phase Microextraction in combination with Gas Chromatography-Mass Spectrometry (HS-SPME-GC-MS). Sixteen sesquiterpenes were identified, mainly hydrocarbons but also derived oxygenated compounds. Sesquiterpenes were acyclic, monocyclic, byciclic and tryciclic. Sesquiterpenes were detected in SIM (selected ion monitoring) mode using their characteristics ions. All the sesquiterpenes were identified by mass spectral data, linear retention indices (LRI), literature data and injection of standards where available. Quantitative results were obtained using the method of standard additions. The method showed an average $\mathrm{LOD}=0.05 \mu \mathrm{g} \mathrm{L}^{-1}$ and $\mathrm{LOQ}=0.15 \mu \mathrm{g} \mathrm{L}^{-1}$. The monocyclic sesquiterpene with the germacrene skeleton, Germacrene D and the bicyclic sesquiterpene with the muurolane skeleton, $\alpha$-muurolene were present in all the wine samples analysed. Syrah wines were the samples richest in sesquiterpenes in agreement with their typical spicy and woody notes. The results evidenced the possibility to use sesquiterpenes for wine authenticity and traceability.
\end{abstract}

Keywords: sesquiterpenes; red wines; HS-SPME-GC-MS

\section{Introduction}

The aroma profile of wine is due to the combined effects of several volatile compounds mainly alcohols, aldehydes, esters, acids, monoterpenes and other minor components, already present in the 
grapes or being formed during the fermentation and maturation process. All these compounds are responsible for their so-called "bouquet" on sniffing the head-space from a glass, and the odour/aroma component (palate/aroma) of the overall flavour perceived on drinking [1]. Primary aromas, also known as varietal aromas, come from or are determined by the type of grapes (grape varietals) used in wine making. From the sensorial point of view they present pleasant aroma descriptors, frequently associated with flower and fruit, among others and very low odour thresholds, allowing their perception at low concentrations.

Among primary aromas, a number of volatiles, which are of terpenic origin, are of great importance [2]. It has emerged from various studies that the terpenoid compounds form the axis for the sensory expression of the wine bouquet; they can be used for varietal characterisation since they are not significantly affected by the fermentation stage [3]. Monoterpenes and sesquiterpenes are the lower molecular weight representatives of the terpenoid fraction; they comprise two and three isoprene units, respectively. A general representation of the biosynthesis of monoterpenes sesquiterpenes, as well as some enzymatic transformations such as oxidation, reduction and dehydration, has been summarised by Croteau [4].

The monoterpenes present in wines are widely studied and the most represented are geraniol, nerol, rose oxides (floral, rose-like), linalool (coriander), linalool oxides (camphoraceous, green), nerol oxide (erbaceous) [5,6]. In Nero d'Avola wines sabinene (light, peppery, herbaceous), $\beta$-pinene (light, pine), limonene (green, citrus), terpinolene (fresh, pine), (E)-rose oxide (flower, geranium), (E)-linalool oxide (sweet, floral), (Z)-linalool oxide (sweet, floral), citronellal (strong, citrus green), linalyl acetate (fruity, citrus), linalool (light, lavander) and neryl acetate (floral, fruity, rose) were identified [7]. However, few studies are concerning the presence of sesquiterpenoids in wine with a limited number of identified compounds. These mainly regard Madeira wines which are known to contain farnesol [8], nerolidol [8,9], $\gamma$-eudesmol [9], $\alpha$-cadinol [9] and $\tau$-muurolol [9]. In 'Baga' wines, as well as in grapes, $\alpha$-muurolene, $\alpha$-calacorene and cadalene were identified [10]. Only a recent paper reports a large number of sesquiterpenes in Cabernet sauvignon obtained by a comprehensive two-dimensional gas chromatography (GC $\times \mathrm{GC})$ time-of-flight mass spectrometry (TOFMS) [11]. In our previous work on white Italian wines, only (E)-nerolidol was identified [1]. Sesquiterpenes have been reported as potential contributors to the health benefits of wine [10]. These compounds are described as possessing anti-inflammatory properties [12], antibacterial properties including enhancement of bacterial susceptibility to antibiotics [13], vanticarcinogenic [14] and antioxidant effects [15]. Since the majority of these compounds occur in micro concentrations in grapes and wines, their quantification is quite difficult. The advantages and drawbacks of different extraction and gas chromatographic techniques used for the determination of sesquiterpenic compounds are reviewed by Petronilho. As results from the review quantitative data are limited [16].

Previousy it was optimized a method for the analyses of volatile constituents in wine, which allowed the identification and quantification of a large number of compounds belonged to different classes of substances [17]. The analytical approach used for the extraction of aroma volatile compounds was the solid-phase microextraction (SPME), followed by capillary gas chromatography-mass spectrometry (GC-MS). SPME-gas chromatography is routinely used for the analysis of volatile in various matrices. It is a fast, sensitive and solvent-less technique easily interfaced with GC-MS. It enables rapid analysis at low operating costs and with no environmental pollution.

This research has focused on the presence of sesquiterpenes in red wine varieties with an aim to identify the sesquiterpenes present in red wines and verify if they can be useful for wine characterization and traceability. 


\section{Experimental Section}

\subsection{Sampling}

The research has been carried out on different red wines produced in Sicily (Italy) in 2013 year by the experimental vinery of the "Regional Institute of wines and oils" (Palermo, Italy). Nine different pure wine varieties were analysed; exactly, Syrah, Merlot, Nero d'Avola, Frappato, Petit Verdot, Refosco, Barbarossa, Sagrantino and Malbec. Eight wines were analysed for each variety, each sample in triplicate, as following described.

\subsection{Volatiles Extraction: HS-SPME}

A $40 \mathrm{~mL}$ vial was filled with $20 \mathrm{~mL}$ of each wine samples. The vial was equipped with a "mininert" valve (Supelco, Bellefonte, PA, USA) that allowed the introduction of the fiber without piercing any septum; the septumless "mininert" vial permitted to avoid extraneous peaks due to possible septum bleeding. Extraction was performed in the headspace vial kept at $30^{\circ} \mathrm{C}$ using a commercially available fiber housed in its manual holder (Supelco, Bellefonte, PA, USA). All extractions were carried out using a DVB/CAR/PDMS fiber, of 50/30 $\mu \mathrm{m}$ film thickness (Supelco, Bellefonte, PA, USA). The samples were equilibrated for $15 \mathrm{~min}$ and then extracted for $15 \mathrm{~min}$. During the extraction, the sample was continuously stirred. After the sampling, the SPME fiber was introduced onto the splitless injector of the GC-MS using the conditions reported below. The fiber was kept in the injector for 3 min for thermal desorption of the analytes onto the capillary GC column. The splitless injector port was maintained at $260{ }^{\circ} \mathrm{C}$. No artefacts were observed after a SPME analysis of the saturated saline solution performed as blank analysis.

\subsection{Volatiles Analysis: GC-MS}

A Varian 3800 gas chromatograph directly interfaced with a Varian 2000 ion trap mass spectrometer (Varian Spa, Milan, Italy) was used. The conditions were as follows: injector temperature, $260{ }^{\circ} \mathrm{C}$; injection mode, splitless; capillary column, CP-Wax $52 \mathrm{CB}, 60 \mathrm{~m}, 0.25 \mathrm{~mm}$ i.d., $0.25 \mu \mathrm{m}$ film thickness (Chrompack Italy, s.r.l. Milan, Italy); oven temperature, $45{ }^{\circ} \mathrm{C}$ held for $5 \mathrm{~min}$, then increased to $80{ }^{\circ} \mathrm{C}$ at a rate of $10{ }^{\circ} \mathrm{C} / \mathrm{min}$ and to $240{ }^{\circ} \mathrm{C}$ at $2{ }^{\circ} \mathrm{C} / \mathrm{min}$; carrier gas, helium at a constant pressure of $10 \mathrm{psi}$; transfer line temperature, $250^{\circ} \mathrm{C}$; acquisition range, $40-200 \mathrm{~m} / \mathrm{z}$; scan rate, 1 scan s-1. Data was acquired in Total Ion Current (TIC). Each component was identified using mass spectral data, NIST'14 (NIST/EPA/NIH Mass Spectra Library, version 2.0, USA), FFNSC (Flavors and Fragrances of Natural and Synthetic Compounds, mass spectral database, version 2.0, Italy), linear retention indices, literature data, and the injection of standards where available. The linear retention indices (LRI) were calculated according to Van den Dool and Kratz [18]. Peaks were considered "identified" when their mass spectral fit values were at the default value of 700 or above; their LRI provided a low match window of \pm 10 index units respect to those from literature and their RT matched to that of standards.

\subsection{Quantitative Analyses}

The sesquiterpenes were quantified: each peak quantified was required to have a minimum signal to noise ratio $(\mathrm{S} / \mathrm{N})$ of 5 . Quantitative results were obtained by using the method of standard additions. 
Standards $\alpha$-gurjunene, $\alpha$-cedrene, (E)- $\beta$-farnesene, valencene and (E)-nerolidol were purchased from Sigma-Aldrich (Milan, Italy) of the highest purity available. To quantify sesquiterpenes, being standards not available, the calibration curve of the most similar carbon skeleton sesquiterpene was used. Stock solutions of individual standards were prepared by dissolving the appropriate amount of each compound in ethyl alcohol (95\%) in order to obtain a final concentration of $0.2 \mathrm{mg} / \mathrm{mL}$. The solutions were stored at under $-30{ }^{\circ} \mathrm{C}$. Furthermore, five different concentrations of each stock solution were added to multiple aliquots of each wine sample. The sample alone was also analysed. Quantification was based on a calibration curve generated by plotting detector response versus the amount spiked of each standard. The peak area of each component in total ion current chromatograms was determined during three replicates, and the average value was calculated.

\section{Results and Discussion}

The optimized method was validated in terms of linearity, precision, detection and quantification limits (Table 1). The calibration curves generated by plotting detector response versus the amount spiked of each standard showed a coefficient of detection $\left(r^{2}\right)>0.99$ for all the quantified volatiles. Detection (LOD) and quantification (LOQ) limits were calculated following the IUPAC approach [19]. The method showed an average $\mathrm{LOD}=0.05 \mu \mathrm{g} \mathrm{L}^{-1}$ and $\mathrm{LOQ}=0.15 \mu \mathrm{g} \mathrm{L}^{-1}$. The precision of the method was carried out by intraday repeatability and intralaboratory reproducibility studies. The repeatability of the developed method was determined by analysing three different aliquots of the same sample under identical experimental conditions in the same day and in different days for the intralaboratory reproducibility. Considering the peak area obtained for each component during the different analyses, the coefficient of variation $(\mathrm{CV})$ resulted $<12 \%$ for all the quantified components. The recovery was determined by the standard addition method: each analyte was spiked in a wine sample used as blank materials at five levels; the spiking levels were $\geq 3$ times the level present in the blank. The extraction recoveries were included between $98.9 \%$ and $102.6 \%$.

Table 1. Analytical features of the proposed method.

\begin{tabular}{|c|c|c|c|c|c|c|}
\hline & $\begin{array}{c}\text { LOD } \\
\left(\mu g \mathbf{L}^{-1}\right)\end{array}$ & $\begin{array}{c}\text { LOQ } \\
\left(\mu \mathrm{g} \mathrm{L}^{-1}\right)\end{array}$ & $\begin{array}{c}\text { Linear range } \\
\left(\mu \mathrm{gL}^{-1}\right)\end{array}$ & $\begin{array}{c}\text { Intraday } \\
\text { repeatability } \\
(\mathrm{RSD})(\%)\end{array}$ & $\begin{array}{c}\text { Interday } \\
\text { Repeatability } \\
\text { (RSD) (\%) }\end{array}$ & $\begin{array}{c}\text { Recovery } \\
(\%)\end{array}$ \\
\hline$\alpha$-Gurjunene & 0.04 & 0.13 & $0.12-1.02$ & 2 & 5 & 94 \\
\hline$\alpha$-Cedrene & 0.04 & 0.13 & $0.12-1.08$ & 1 & 4 & 99 \\
\hline (E)- $\beta$-Farnesene & 0.05 & 0.16 & $0.14-0.24$ & 2 & 3 & 98 \\
\hline Valencene & 0.03 & 0.10 & $0.10-1.31$ & 2 & 3 & 97 \\
\hline (E)-Nerolidol & 0.07 & 0.23 & $0.20-5.98$ & 1 & 4 & 104 \\
\hline
\end{tabular}

Table 2 reports all the identified sesquiterpenes together with their retention time (RT), linear retention index (LRI) and odor; quantitative data are reported in Table 3. Sixteen sesquiterpenes, acyclic, monocyclic, bicyclic and tricyclic, were identified mainly hydrocarbons but also derived oxygenated compounds. The structures of each sesquiterpene is reported in Figure 1 while Figure 2 reported the HS-SPME-GC-MS chromatogram of a wine sample in SIM mode monitoring the following ions: $\mathrm{m} / \mathrm{z}$ 161, $\mathrm{m} / \mathrm{z}$ 189, $\mathrm{m} / \mathrm{z} 204 \mathrm{~m} / \mathrm{z}$. 
Table 2. Retention Time (RT), Linear Retention Indexes (LRI) and odour for each sesquiterpene identified in red wine samples.

\begin{tabular}{|c|c|c|c|c|c|}
\hline & Compounds & RT & LRI & IUPAC name & Odour \\
\hline 1) & $\alpha$-Gurjunene * & 35.54 & 1550 & (1aR,4R,4aR,7bS)-1,1,4,7-tetramethyl-1a,2,3,4,4a,5,6,7b-octahydro-1H-cyclopropa[e]azulene & balsamic, woody \\
\hline 2) & $\alpha$-Cedrene * & 36.60 & 1568 & (3R-(3a,3ab,7b,8aa))-2,3,4,7,8,8a-hexahydro-3,6,8,8-tetramethyl-1H-3a,7-methanoazulene & woody, cedar sweet fresh \\
\hline 3) & $\alpha$-Aromadendrene & 41.85 & 1658 & $\begin{array}{l}\text { (1aR,7S,7bS)-1,1,7-trimethyl-4-methylidene-2,3,4a,5,6,7,7a,7b-octahydro-1aH- } \\
\text { cyclopropa[e]azulene }\end{array}$ & woody \\
\hline 4) & $(\mathrm{E})-\beta$-Farnesene $*$ & 42.36 & 1671 & (6E)-7,11-dimethyl-3-methylidenedodeca-1,6,10-triene & woody, citrus, sweet \\
\hline 5) & D Germacrene & 42.67 & 1674 & (S,1Z,6Z)-8-isopropyl-1-methyl-5-methylenecyclodeca-1,6-diene & weak fruity, apple like \\
\hline 6) & Valencene * & 43.12 & 1680 & 4a,5-dimethyl-3-prop-1-en-2-yl-2,3,4,5,6,7-hexahydro-1H-naphthalene & citrus, green, woody \\
\hline 7) & $\gamma$-Gurjunene & 43.30 & 1684 & (1R,4R,7R)-1,4-dimethyl-7-prop-1-en-2-yl-1,2,3,3a,4,5,6,7-octahydroazulene & musty \\
\hline 8) & (E)- $\beta$-Bisabolene & 44.03 & 1697 & (4R)-1-methyl-4-(6-methylhepta-1,5-dien-2-yl)cyclohexene & balsamic, woody, spicy \\
\hline 9) & $\delta$-Cadinene & 44.89 & 1711 & (1S,8aR)-4,7-dimethyl-1-(propan-2-yl)-1,2,3,5,6,8a-hexahydronaphthalene & woody, weak, medicinal \\
\hline 10) & $\beta$-Selinene & 45.26 & 1718 & $\begin{array}{l}\text { 3S,4aR,8aS)-8a-methyl-5-methylidene-3-prop-1-en-2-yl-1,2,3,4,4a,6,7,8- } \\
\text { octahydronaphthalene }\end{array}$ & herbal \\
\hline 11) & $\alpha$-Muurolene & 45.62 & 1721 & (1S,4aS,8aR)-1-isopropyl-4,7-dimethyl-1,2,4a,5,6,8a-hexahydronaphthalene & woody, floral, herbal \\
\hline 12) & $\alpha$-Selinene & 45.68 & 1725 & 5,8a-dimethyl-3-prop-1-en-2-yl-2,3,4,4a, 7,8-hexahydro-1H-naphthalene & amber \\
\hline 13) & (Z)- $\alpha$-Bisabolene & 48.12 & 1768 & 1-methyl-4-(6-methylhepta-2,5-dien-2-yl)cyclohexene & balsamic, spicy \\
\hline 14) & (E)-Nerolidol * & 61.84 & 2024 & (6E)-3,7,11-trimethyldodeca-1,6,10-trien-3-ol & floral, green, citrus, woody \\
\hline 15) & Viridiflorol & 68.49 & 2155 & $\begin{array}{l}\text { (1aR,4S,4aS,7R,7aS)-1,1,4,7-tetramethyl-2,3,4a,5,6,7,7a,7b-octahydro-1aH- } \\
\text { cyclopropa[e]azulen-4-ol }\end{array}$ & sweet, green \\
\hline 16) & $\gamma$-Eudesmol & 69.10 & 2167 & 2-[(2R,4aR)-4a,8-dimethyl-2,3,4,5,6,7-hexahydro-1H-naphthalen-2-yl]propan-2-ol & rose, apple, green, citrus \\
\hline
\end{tabular}

\footnotetext{
* standards available.
} 
Table 3. Average amount * of sesquiterpenes in the red wines analysed.

\begin{tabular}{|c|c|c|c|c|c|c|c|c|c|c|c|c|c|c|c|c|c|c|}
\hline $\begin{array}{l}\text { Compounds } \\
\left(\mu \mathrm{g} \mathrm{L}^{-1}\right)\end{array}$ & Syrah & $\begin{array}{l}\text { CV } \\
\% \\
\end{array}$ & Merlot & $\begin{array}{l}\text { CV } \\
\% \\
\end{array}$ & $\begin{array}{c}\text { Nero } \\
\text { d'Avola } \\
\end{array}$ & $\begin{array}{l}\text { CV } \\
\% \\
\end{array}$ & Frappato & $\begin{array}{l}\text { CV } \\
\% \\
\end{array}$ & $\begin{array}{c}\text { Petit } \\
\text { Verdot } \\
\end{array}$ & $\begin{array}{l}\text { CV } \\
\% \\
\end{array}$ & Refosco & $\begin{array}{l}\text { CV } \\
\% \\
\end{array}$ & Barbarossa & $\begin{array}{c}\text { CV } \\
\% \\
\end{array}$ & Sagrantino & $\begin{array}{c}\text { CV } \\
\% \\
\end{array}$ & Malbec & $\begin{array}{l}\mathrm{CV} \\
\% \\
\end{array}$ \\
\hline$\alpha$-Gurjunene & $\operatorname{tr}$ & - & - & - & $\operatorname{tr}$ & - & $\operatorname{tr}$ & - & $\operatorname{tr}$ & - & - & - & - & - & - & - & - & - \\
\hline$\alpha$-Cedrene & - & - & - & - & - & - & - & - & $\operatorname{tr}$ & - & - & - & - & - & - & - & - & - \\
\hline$\alpha$-Aromadendrene & - & - & - & - & - & - & - & - & - & - & 0.21 & 5 & - & - & - & - & - & - \\
\hline (E)- $\beta$-Farnesene & $\operatorname{tr}$ & - & - & - & $\operatorname{tr}$ & - & $\operatorname{tr}$ & - & - & - & - & - & - & - & - & - & - & - \\
\hline D Germacrene & 1.01 & 11 & 0.70 & 16 & 0.41 & 6 & 0.20 & 9 & $\operatorname{tr}$ & - & 0.13 & 7 & 0.19 & 13 & 0.34 & 13 & 0.19 & 6 \\
\hline Valencene & 0.10 & 7 & - & - & $\operatorname{tr}$ & - & - & - & 0.12 & 7 & - & - & - & - & $\operatorname{tr}$ & - & $\operatorname{tr}$ & - \\
\hline$\gamma$-Gurjunene & 1.40 & 14 & - & - & - & - & - & - & - & - & - & - & - & - & - & - & - & - \\
\hline (E)- $\beta$-Bisabolene & $\operatorname{tr}$ & - & - & - & $\operatorname{tr}$ & - & - & - & - & - & - & - & - & - & - & - & - & - \\
\hline$\delta$-Cadinene & $\operatorname{tr}$ & - & $\operatorname{tr}$ & - & 0.10 & 9 & $\operatorname{tr}$ & - & - & - & - & - & - & - & - & - & - & - \\
\hline$\beta$-Selinene & - & - & - & - & - & - & - & - & $\operatorname{tr}$ & - & - & - & - & - & - & - & - & - \\
\hline$\alpha$-Muurolene & 1.69 & 12 & 0.11 & 8 & 0.98 & 12 & 0.24 & 12 & 0.97 & 6 & 0.28 & 14 & 0.30 & 9 & $\operatorname{tr}$ & - & 1.25 & 4 \\
\hline$\alpha$-Selinene & - & - & 0.12 & 17 & - & - & - & - & - & - & - & - & 0.31 & 16 & 0.38 & 9 & - & - \\
\hline (Z)- $\alpha$-Bisabolene & - & - & - & - & - & - & - & - & $\operatorname{tr}$ & - & - & - & - & - & $\operatorname{tr}$ & - & 0.19 & 14 \\
\hline (E)-Nerolidol & 5.43 & 5 & - & - & - & - & - & - & - & - & - & - & - & - & 2.39 & 6 & - & - \\
\hline Viridiflorol & - & - & - & - & 2.76 & 13 & - & - & - & - & - & - & - & - & - & - & - & - \\
\hline$\gamma$-Eudesmol & - & - & - & - & - & - & - & - & - & - & - & - & - & - & $\operatorname{tr}$ & - & - & - \\
\hline All & 9.63 & & 0.93 & & 4.25 & & 0.44 & & 1.09 & & 0.62 & & 0.81 & & 3.11 & & 1.63 & \\
\hline
\end{tabular}

* Average amount of 24 samples of wine analyzed. 
Acyclic sesquiterpenes<smiles>C=CC(=C)CC/C=C(\C)CCC=C(C)C</smiles>

(E)- $\beta$-Farnesene

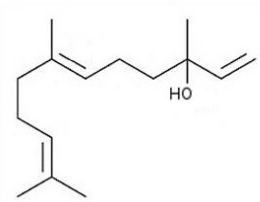

(E)-Nerolidol

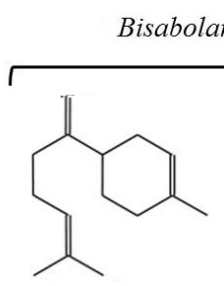

(E)- $\beta$-Bisabolene
Monocyclic Sesquiterpenes

Germacrene skeleton

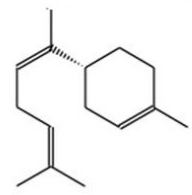

(Z)- $\alpha$-Bisabolene

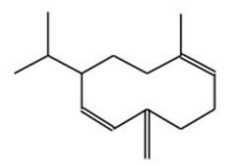

D Germacrene

Byciclic sesquiterpenes

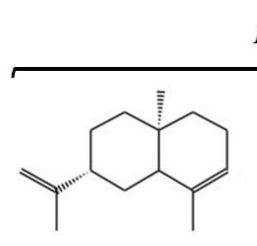

$\alpha$-Selinene<smiles>C=C(C)[C@@H]1CC[C@]2(C)CCCC(=C)[C@]2(C)C1</smiles>

$\beta$-Selinene

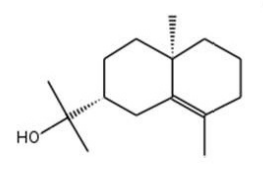

$\gamma$-Eudesmol

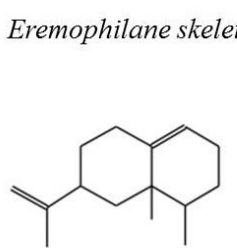

Valencene

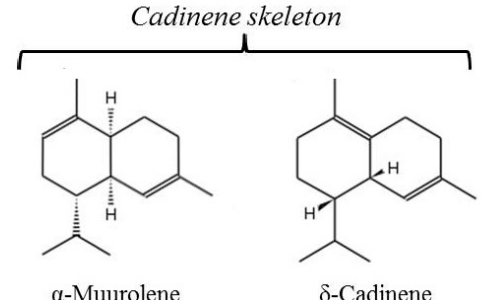

Tricyclic sesquiterpenes Cedrane skeleton

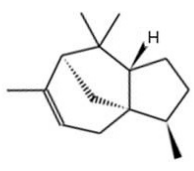

$\alpha$-Cedrene

$\delta$-Cadinene
Guaiane skeleton

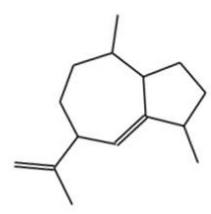

$\gamma$-Gurjunene

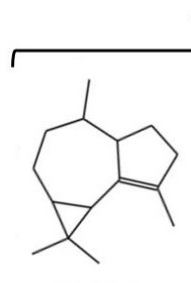

$\alpha$-Gurjunene
Aromadendrene skeleton

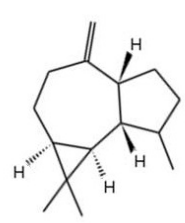

$\alpha$-aromadendrene

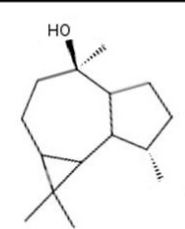

Viridiflorol
Figure 1. Structure of the sesquiterpenes identified in the analyzed wines samples.

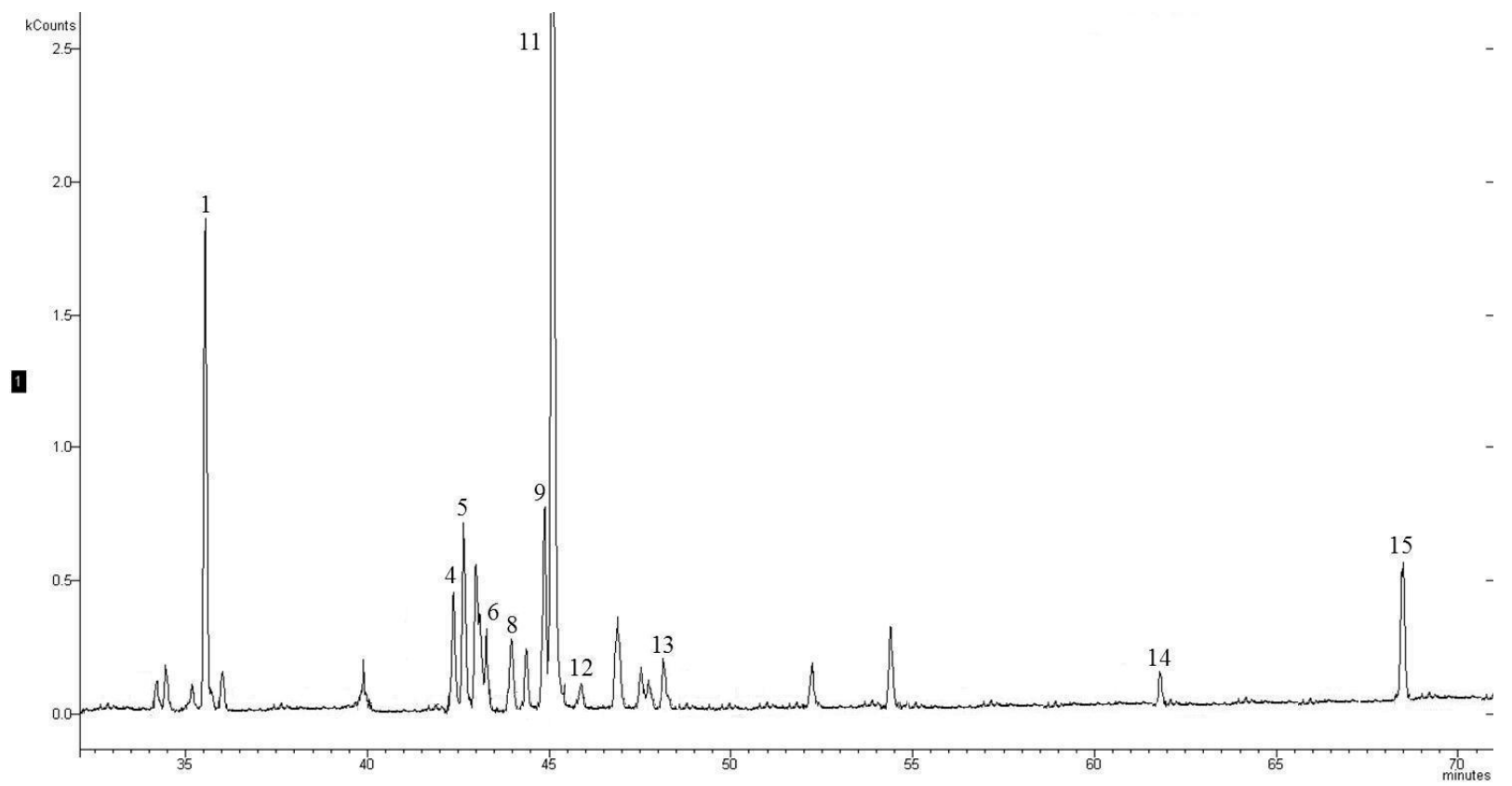

Figure 2. Headspace Solid-Phase Microextraction coupled with Gas Chromatography-Mass Spectrometry (HS-SPME-GC-MS) chromatogram (SIM: $m / z=161.0+189.0+204.0$ ) of a wine sample. For peak identification see Table 2. 
As regards the acyclic sesquiterpenes, $\beta$-farnesene and (E)-nerolidol were identified: $\beta$-farnesene was present only as traces in Syrah, Nero d'Avola and Frappato wines, whereas (E)-nerolidol in Syrah and Sagrantino with $5.43 \mu \mathrm{g} \mathrm{L}^{-1}$ and $2.39 \mu \mathrm{g} \mathrm{L}^{-1}$ respectively. These sesquiterpenic compounds can be related with the floral characteristics of wines and derives from farnesyl diphosphate, an intermediate in isoprenoid and ergosterol biosynthesis at acidic $\mathrm{pH}$, the instability of the diphosphate group leads to the release of Farnesol and its isomer Nerolidol [20]. They were identified in different wine varieties and in the Italian white wines Grillo, Inzolia and Cataratto $[1,10,16]$.

As regards the monocyclic sesquiterpenes, two compounds with the bisabolane skeleton, (E)- $\beta$ bisabolene and (Z)- $\alpha$-bisabolene, and one with the germacrene skeleton, Germacrene $D$, were identified. Bisabolenes derive from farnesyl diphosphate. (E)- $\beta$-bisabolene was identified in traces in Syrah and in Nero d'Avola wines, (Z)- $\alpha$-bisabolene was present in Malbec $\left(0.19 \mu \mathrm{g} \mathrm{L}^{-1}\right)$ and, as traces, in Petiti Verdot and Sagrantino. Germacrene D was identified in all the wine samples analysed with an amount ranged between traces and $1.01 \mu \mathrm{g} \mathrm{L}^{-1}$. It is considered a precursor of many sesquiterpene hydrocarbons such as cadinane, eudesmane (selinane), oppositane, axane, isodaucane, and bourbonane [21] and is one of the Vitis vinifera L. sesquiterpenoids reported to occur in grapes, both red and white varieties [10].

Among the byclic sesquiterpenes, $\alpha$ and $\beta$-selinene and $\gamma$-eudesmol were identified. They are bicyclic eudesmane sesquiterpenes which are thought to be derived from further cyclization of the monocyclic germacranes. $\beta$-Selinene and $\gamma$-eudesmol were identified as traces in Petit Verdot and Sagrantino, respectively, while $\alpha$-selinene in Merlot, Barbarossa and Sagrantino.

Valencene was identified, too. Valencene is a volatile sesquiterpene emitted from flowers of grapevine, Vitis vinifera L., this compound has the eremophilane skeleton which derives from the eudesmane skeleton by migration of the C-10 methyl group to C-5 [22]. The highest amount resulted in Syrah and Petit Verdot.

The murolane/cadinane group of bicyclic sesquiterpenes were represented only by $\alpha$-muurolene and $\delta$-cadinene. In the cadinane skeleton, the decalin ring is trans-fused $(1 \alpha, 6 \beta, 7 \beta)$, while in the muurolane skeleton $(1 \beta, 6 \beta, 7 \beta)$ it is cis-fused. $\alpha$-Muurolene and $\alpha$-cadinene were reported in different wines and grapes $[10,16]$. $\alpha$-Muurolene was present in all the wine samples analysed with the highest amount in Syrah and Malbec and the lowest in Sagrantino. $\delta$-Cadinene was identified only in Nero d'Avola, Syrah, Merlot and Frappato but in low amount.

Among byciclic sesquiterpenes $\gamma$-gurjunene was identified only in Syrah wines. It is a guaiene sesuiterpene which contain fused 5 and 7 membered rings. Guaianes are often present together with eudesmanes and may be derived by an alternative cyclization of the same germacrane precursor which gives rise to eudesmanes [23].

$\alpha$-Gurjunene, $\alpha$-aromadendrene and viridiflorol, aromadendrane sesquiterpenes, are 6,11-cycloguaianes in which an additional cyclopropyl ring has been formed by further cyclization of a guaiane precursor. $\alpha$-Gurjunene was identified in Syrah, Nero d'Avola, Frappato and Petit Verdot wines, $\alpha$-aromadrendrene in Refosco and viridiflorol in Nero d'Avola. Aromadendrene has been already identified by other Authors in Cabernet Sauvignon wine [11].

Among guaine derivatives, rotundone was not present in the wine samples analyzed. This sesquiterpene ketone is considered responsible for the peppery character of Syrah wines and it has been reported to be present in Australian Syrah wines in an amount ranged between 0.029 and $0.15 \mu \mathrm{g} \mathrm{L}^{-1}$ [24]. Rotundone concentration in musts and wines may depend on several factors such as cultivar, region and 
mesoclimate; in particular, lower temperatures may result in increased rotundone accumulation $[25,26]$, in fact Mayr, studying the key aroma compounds in Syrah wine, found the lowest value for rotundone $(0.001 \mu \mathrm{g} / \mathrm{L})$ in warm grape-growing region in South Australia [27].

The GC-MS conditions applied in this research were able to detect compounds up to 2500 LRI value. The LRI reported in literature for rotundone is 2280 [24], consequently if rotundone was present in our samples it would be in a very low amount (below the limit of detection) in agreement with the demonstrated effects of climate on rotundone accumulation since the Syrah wines analyzed came from the Mediterranean area.

$\alpha$-Cedrene (cedrane skeleton) is a tricyclic sesquiterpene typical of the cedarwood oil [11], already reported in Cabernet Sauvignon [28]. Among the analyzed samples it was identified as traces only in Petit Verdot wines.

From the Table 3, qualitative and quantitative differences resulted among the analyzed wines. It is well-known that terpenes play an important role in grape and wine aromas to the extent that monoterpenes are considered to be important for the varietal character and for varietal and clonal discrimination [25]. Sesquiterpenes are synthesized via the mevalonate (MVA) pathway localized in the cytosol and the remarkable diversity of sesquiterpenes is generated by the large family of sesquiterpene synthases (TPS-a), recently discovered in grapes, each producing multiple substrates [29]. Further research demonstrated that grapes produce numerous sesquiterpene hydrocarbons with a characteristic profile depending on the variety and the developmental stage [30].

In the field of food traceability, sesquiterpenes were also used for olive oils and cheeses. In details, Zunin indicated that $\alpha$-copaene, $\alpha$-muurolene and $\alpha$-farnesene can be used for discriminating olive oils produced in West Liguria from oils produced in other Mediterranean regions [31], whereas Favaro proposed $\beta$-caryophyllene and $\alpha$-humulene for the traceability of Asiago mountain cheese [32].

In this context and followed our results, volatile sesquiterpenes show the potential to discriminate the wine variety.

\section{Conclusions}

The HS-SPME-GC-MS method applied to the different varieties of red wines allowed the identification of a large number of sesquiterpenes. The identified sesquiterpenes were mainly hydrocarbons but also oxygenated compounds. The method also allowed their quantitative determination since the low limit of quantification of the developed method. Among the sesquiterpenes, only $\alpha$ muurolene and germacrene D were identified in all the wines, even if in different amount. Other sesquiterpenes, such as $\alpha$-cedrene, $\alpha$-aromadendrene, $\gamma$-gurjunene, $\delta$-selinene viridiflorol and $\gamma$-eudesmol were present in only one variety, namely Petit Verdot, Refosco, Syrah, Petit Verdot, Nero d'Avola and Sagrantino respectively. From the results, Syrah samples were those richest in sesquiterpenes, Frappato the poorest ones. It is known that sesquiterpenes have very low odour threshold, in the range of ppb, therefore it is presumable that the many of the sesquiterpenes here quantified exceeded their odor threshold. Sesquiterpenes contribute to the spicy and woody notes of wines with a synergistic effect. In this context, the highest amount of sesquiterpenes in Syrah samples was in agreement with the spicy and pepper notes which are typical of this variety of wine. Further analyses are required on a larger number of wine varieties to verify the possibility of using sesquiterpenes for wine traceability and authenticity. 


\section{Acknowledgements}

We wish to thank the Regional Istitute of Wine and Oil of Palermo for providing wine samples.

\section{Author Contributions}

F. Cincotta: bibliography compilation, manuscript writing; G. Tripodi and C. Condurso: analyses; A. Verzera: initial design, supervision and manuscript revision.

\section{Conflicts of Interest}

The authors declare no conflict of interest.

\section{References}

1. Scacco, A.; Oliva, D.; Di Maio, S.; Polizzotto, G.; Genna, G.; Tripodi, G.; Verzera, A. Indigenous Saccharomyces Cerevisiae strains and their influence on the quality of Cataratto, Inzolia and Grillo white wines. Food Res. Int. 2012, 46, 1-9.

2. Marais, J. Terpenes in the aroma of grapes and wines: A review. S. Afr. J. Enol. Vitic. 1983, 4, 49-60.

3. Tominaga, T.; Murat, M.L.; Dubourdieu, D. Development of a method for analyzing the volatile thiols involved in the characteristic aroma of wines made from Vitis vinifera L. cv. Sauvignon blanc. J. Agric. Food Chem. 1998, 46, 1044-1048.

4. Croteau, R. Biosynthesis of monoterpenes and sesquiterpenes. Geruch- und Geschmackstoffe. Verlag Hans Carl Numberg 1975, 153-166.

5. Meilgaard, M.C. Flavor chemistry of beer. Flavor interaction between principal volatiles. Tech. $Q$. Mast. Brew Assoc. Am. 1975, 12, 107-117.

6. Simpson, R.F. Some important aroma components of white wine. Food Technol. 1979, 31, 516-522.

7. Verzera, A.; Tripodi, G.; Dima, G.; Condurso, C.; Scacco, A.; Cincotta, F.; Giglio, D.M.L.; Sparacio, A. Leaf Removal and Wine Composition of Vitis vinifera L. cv. Nero d'Avola. The volatile aroma constituents. J. Sci. Food Agric. 2015, in press.

8. Câmara, J.S.; Herbert, P.; Marques, J.C.; Alves, M.A. Varietal flavour compounds of four grape varieties producing Madeira wines. Anal. Chim. Acta 2004, 513, 203-207.

9. Alves, R.F.; Nascimento, A.M.D.; Nogueira, J.M.F. Characterization of the aroma profile of Madeira wine by sorptive extraction techniques. Anal. Chim. Acta 2005, 546, 11-21.

10. Rocha, S.M.; Coelho, E.; Vinholes, J.; Coimbra, M.A. Grapes and wine from Vitis vinifera L. as a potential source of sesquiterpenoids. In Natural Products, Series Recent Progress in Medicinal Plants; Editions Studium Press LLC: Huston, TX, USA, 2006; Volume 15, Chapter 12, pp. 253-272.

11. Robinson, A.L.; Boss, P.K.; Heymann, H.; Solomon, P.S.; Trengove, R.D. Development of a sensitive non-targeted method for characterizing the wine volatile profile using headspace solidphase microextraction comprehensive two-dimensional gas chromatography time-of-flight mass spectrometry. J. Chromatogr. A 2011, 1218, 504-517.

12. Fernandes, E.S.; Passos, G.F.; Medeiros, R.; da Cunha, F.M.; Ferreira, J.; Campos, M.M.; Calixto, J.B. Anti-inflammatory effects of compounds alpha-humulene and (-)-trans-caryophyllene isolated from the essential oil of Cordia verbenacea. Eur. J. Pharmacol. 2007, 569, 228-236. 
13. Gonçalves-Pereira, J.; Póvoa, P. Antibiotics in critically ill patients: A systematic review of the pharmacokinetics of $\beta$-lactams. Crit. Care 2011, 15, 13.

14. Tatman, D.; Mo, H. Volatile isoprenoid constituents of fruits, vegetables and herbs cumulatively suppress the proliferation of murine B16 melanoma and human HL-60 leukemia cells. Cancer Lett. 2002, 175, 129-139.

15. Ruberto, G.; Baratta, M.T. Antioxidant activity of selected essential oil components in two lipid model systems. Food Chem. 2000, 69, 167-174.

16. Petronilho, S.; Coimbra, M.A.; Rocha, S.M. A critical review on extraction techniques and gas chromatography based determination of grapevine derived sesquiterpenes. Anal. Chim. Acta 2014, $846,8-35$.

17. Verzera, A.; Ziino, M.; Scacco, A., Lanza, C. M.; Mazzaglia, A.; Romeo, V.; Condurso, C. Volatile compound and sensory analysis for the characterization of an Italian white wine from "Inzolia" grapes. Food Anal. Methods 2008, 1, 144-151.

18. Van den Dool, H.; Kratz, P.D. A generalization of the retention index systemincluding linear temperature programmedgas-liquid partition chromatography. J. Chromatogr. A 1963, 11, 463-471.

19. McNaught, A.D. Compendium of chemical terminology. In IUPAC Compendium of Chemical Terminology; Blackwell Science: Oxford, UK, 1997; Volume 1669.

20. Steyer, D.; Ambroset, C.; Brion, C.; Claudel, P.; Delobel, P.; Sanchez, I.; Legras, J.L. QTL mapping of the production of wine aroma compounds by yeast. BMC Genomics 2012, 13, 573.

21. Schmidt, C.O.; Bouwmeester, H.J.; Franke, S.; König, W.A. Mechanisms of the biosynthesis of sesquiterpene enantiomers (+)-and (-)-germacrene D in Solidago Canadensis. Chirality 1999, 11, 353-362.

22. Lücker, J.; Bowen, P.; Bohlmann, J. Vitis vinifera terpenoid cyclases: functional identification of two sesquiterpene synthase cDNAs encoding (+)-valencene synthase and (-)-germacrene D synthase and expression of mono-and sesquiterpene synthases in grapevine flowers and berries. Phytochemistry 2004, 65, 2649-2659.

23. Brown, G.D. The biosynthesis of artemisinin (Qinghaosu) and the phytochemistry of Artemisia annua L. (Qinghao). Molecules 2010, 15, 7603-7698.

24. Wood, C.; Siebert, T.E.; Parker, M.; Capone, D.L.; Elsey, G.M., Pollnitz, A.P.; Egger, M.; Meier, M.; Vossing, T.; Widder, S.; et al. From wine to pepper: rotundone, an obscure sesquiterpene, is a potent spicy aroma compound. J. Agric. Food Chem. 2008, 56, 3738-3744.

25. Caputi, L.; Carlin, S.; Ghiglieno, I.; Stefanini, M.; Valenti, L.; Vrhovsek, U.; Mattivi, F. Relationship of changes in rotundone content during grape ripening and winemaking to manipulation of the 'peppery' character of wine. J. Agric. Food Chem. 2011, 59, 5565-5571.

26. Scarlett, N.J.; Bramley, R.G.V.; Siebert, T.E. Within-vineyard variation in the "pepper" compound rotundone is spatially structured and related to variation in the land underlying the vineyard. Aust. J. Grape Wine Res. 2014, 20, 214-222.

27. Mayr, C.M.; Geue, J.P.; Holt, H.E.; Pearson, W.P.; Jeffery, D.W.; Francis, I.L. Characterization of the key aroma compounds in Shiraz wine by quantitation, aroma reconstitution, and omission studies. J. Agric. Food Chem. 2014, 62, 4528-4536.

28. Adams, R.P.; Li, S. The botanical source of Chinese cedarwood oil: Cupressus funebris or Cupressaceae species? J. Essent. Oil Res. 2008, 20, 235-242. 
29. Martin, D.M.; Aubourg, S.; Schouwey, M.B.; Daviet, L.; Schalk, M.; Toub, O.; Lund, S.T.; Bohlmann, J. Functional annotation, genome organization and phylogeny of the grapevine (Vitis vinifera) terpene synthase gene family based on genome assembly, FLcDNA cloning, and enzyme assays. BMC Plant Biol. 2010, 10, 226.

30. May, B.; Wüst, M. Temporal development of sesquiterpene hydrocarbon profiles of different grape varieties during ripening. Flavour Fragrance J. 2012, 27, 280-285.

31. Zunin, P.; Boggia, R.; Salvadeo, P.; Evangelisti, F. Geographical traceability of West Liguria extravirgin olive oils by the analysis of volatile terpenoid hydrocarbons. J. Chromatogr. A 2005, 1089, 243-249.

32. Favaro, G.; Magno, F.; Boaretto, A.; Bailoni, L.; Mantovani, R. Traceability of Asiago mountain cheese: A rapid, low-cost analytical procedure for its identification based on solid-phase microextraction. J. Dairy Sci. 2005, 88, 3426-3434.

(C) 2015 by the authors; licensee MDPI, Basel, Switzerland. This article is an open access article distributed under the terms and conditions of the Creative Commons Attribution license (http://creativecommons.org/licenses/by/4.0/). 